\title{
A Customized Semi- Precision Bar Attachment for Tooth Supported Overdenture: A Case Report
}

Various precision attachment systems are available for tooth supported overdenture treatment modality. The objective of all the systems is to provide retention and support for the overdenture. Retention of a mandibular denture can be achieved by natural tooth-retained with bar and stud attachment in anterior region. A simple and cost effective treatment for a more complex implant overdenture is the concept of conventional tooth-retained overdentures. The present clinical report describes a patient treated with customized hader bar with coffee straw in mandibular tooth-borne overdenture.

KEYWORDS: Customized hader bar, Tooth supported overdenture

\section{INTRODUCTION}

The statement by Dr. Muller DeVan "Perpetual preservation of what remains is more important than the meticulous replacement of what is missing" still sounds factual. Preventive prosthodontics emphasizes the importance of any procedure that can delay or eliminate future prosthodontic problems. Overdenture is one such preventive treatment modality which helps in delaying the process of resorption thereby improving the denture foundation area, enhancing the masticatory efficiency of the patient.' Among various attachments like the Dolder bar (Dolder Bar System; Attachments Intl, Inc, Burlingame, Calif.) and the Hader bar (HaderEDS Bar System; Attachments Intl, Inc.) are the most commonly used attachments for overdentures and implant retained restorations. But the disadvantage these extracoronal attachments bar systems is that they are expensive. $^{2}$

\section{CASE REPORT}

A 55-year-old male patient approached the Department of Prosthodontics, Teerthanker Mahaveer Dental College and Hospital to get his missing teeth replaced. On examination it was observed that he had a completely edentulous maxillary arch and a partially edentulous mandibular arch with Kennedy's type I modification 1 . Totally five teeth were present in the oral cavity, mandibular canine and first bicuspid on both the left and right side and second bicuspid on the right side of the arch (Figure 1).
Patient gave the history of teeth loss due to multiple caries and periodontal problems. Since ten years the patient was wearing removable partial dentures. He wanted to get his partial dentures remade as they were ill fitting and not efficiently serving the purpose. No mobility and periapical pathology was noticed in the clinical and radiographical examination. The patient wanted well-fitting dentures as compared to his old ones.

\section{TREATMENT PLAN}

After oral examination the impressions were made and the casts were retrieved which were used for the assessment of the inter-arch distance. As the overdenture requires additional interarch distance to accommodate it's attachments and the denture base, it was required to examine the same. Thus a tentative jaw relation was recorded and the casts were mounted on an articulator. In the present case, a sufficient space was found to be there to accommodate the bar supported over mandibular final impression that was made with elastomeric impression material ${ }_{3} \mathrm{M}$ putty and light body) and the cast was poured in dental stone (figure 2). The wax pattern for the copings was made and a coffee plastic straw was attached to the wax patterns splinting the right and left abutment teeth (figure 3). A putty index was made for the metal housing and a mould was fabricated by using the pattern resin.

Both coffee straw and bar framework with metal housing mould was invested, burned-out and cast 
according to the manufacturer's instructions (figure 4).

The hader clips were checked onto the cast metal housing and the cast bar framework was adjusted to fit the master cast (figure 5). The finished and polished bar was tried in the patient's mouth and the fit was checked (figure 6).

Complete dentures were fabricated by using the conventional methods. The yellow hader clips with metal housing were embedded in the intaglio surface of the lower denture(figure 7 ). Finally the bar was cemented using self cure resin. The upper and lower dentures were placed.

\section{DISCUSSION}

Various extracoronal attachment systems that are easily available in the market are used for the fabrication of overdenture. Among all, dolder and hader bars are the most commonly used extraoral attachment systems for the overdentures. Overdenture with attachments can redirect the occlusal forces away from the weak supporting abutment teeth and onto a soft tissue or redirect them toward stronger abutments thereby resulting in superior retention. ${ }^{3}$ The use of stress breakers is always advisable whenever the load is expected to jeopardize the existing condition of the abutment teeth. The bar attachment offers slight vertical and rotational movement of the denture as well as a stress breaker action. Bar exhibits more cross-arch involvement and allows occlusal forces to be shared between the abutments. ${ }^{4}$ Now a days implant treatment has become the custom, thus tooth supported overdentures have taken a backseat as a result of competitive commercialization of implants in field of dentistry. ${ }^{5}$ Still it has been a boon to the preventive prosthodontics to save the teeth thus saving the bone. It is the most acceptable treatment for those who cannot afford the high implant cost and also those who are medically unfit to undergo surgery. The tooth supported overdenture forefront the preventive prosthodontic modalities; this requires more innovation to make it the most beneficial and economical regular clinical practice.

\section{CONCLUSION}

The objective of removable/fixed partial denture is retention, stability, support and esthetics. The above described method is a cost effective technique and fulfills all the objectives.

\section{REFRENCES}

1. Renner RP, Gomes BC, Shakun ML, Baer PN, Davis RK, Camp P. Four-year longitudinal study of the periodontal health status of overdenture patients. J Prosthet Dent 1984;51:593-8.

2. Mensor MC Jr. Attachment fixation of the overdenture: part II. J Prosthet Dent 1978;39:16-20.

3. Bambara GE. The attachment-retained overdenture. N Y State Dent J 2004;70:30-3.

4. Evans DB, Koeppen RG. Bar attachments for overdentures with nonparallel abutments. J Prosthet Dent 1992;68:6-11.

5. Williamson RT. Retentive bar overdenture fabrication with preformed castable components: A case report. Quintessence Int1994;25:389-94.
Source of support: Nil, Conflict of interest: None declared
Cite this article as:

Khan M, Sahu K, Singh K, Jhadav S. A Customized Semi- Precision Bar

Attachment for Tooth Supported Overdenture: A Case Report. Int Healthcare Res J 2018;2(4):89-91. doi: 10.26440/IHRJ/02_04/181

\section{AUTHOR AFFILIATIONS:}

MDS, Senior Resident, GTB Hospital, New Delhi.

MDS (Private Practitioner)

MDS (Private Practitioner)

MDS (Private Practitioner)

\section{Corresponding Author:}

Dr. Mohsin Khan

13. West Laxmi Market

P.O. Krishna Nagar

New Delhi 110051
For article enquiry/author contact details, e-mail at: manuscriptenquiry.ihrj@gmail.com 


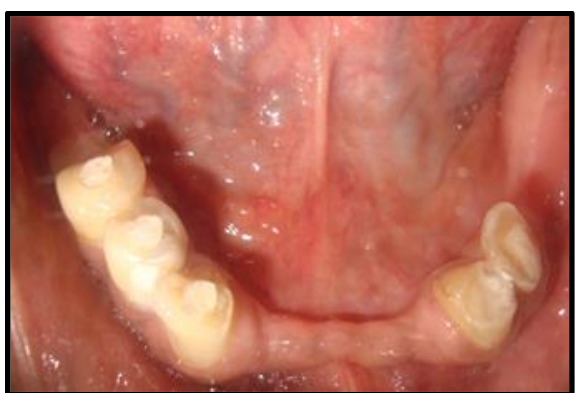

Figure 1. Intentional Root Canal Treatment of Abutment Teeth

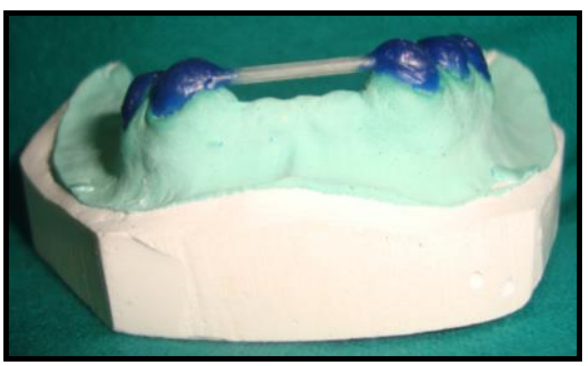

Figure 3. Fabrication Pf Wax Pattern and Attachment Of Coffee Straw

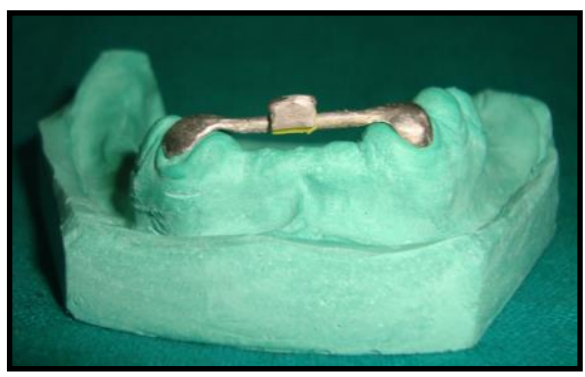

Figure 5. Checking Of Metal Housing and Hader Clip On Bar

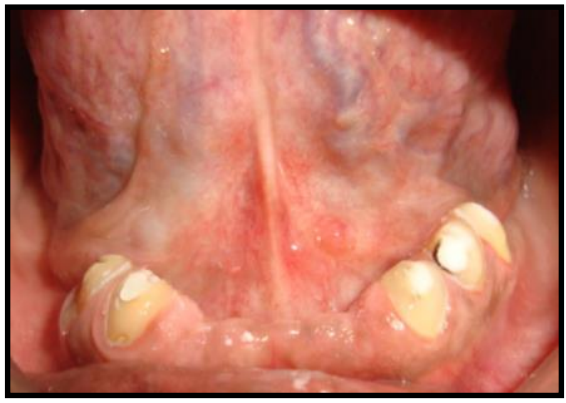

Figure 2. Dome Shape Preparation with Chamfer Finish Line

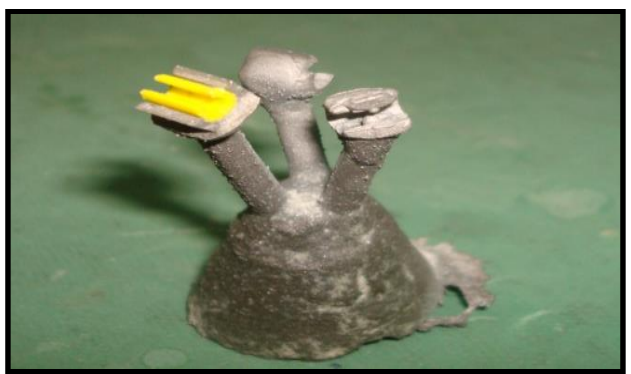

Figure 4. Casting Of Metal Housing and Attachment Of Hader Clip

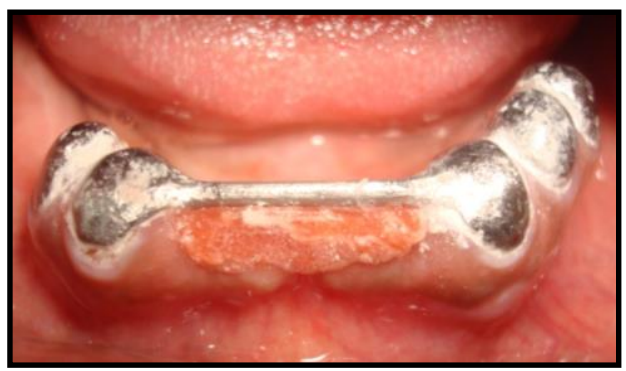

Figure 6. Cementation Of Customized Bar in Patient Mouth

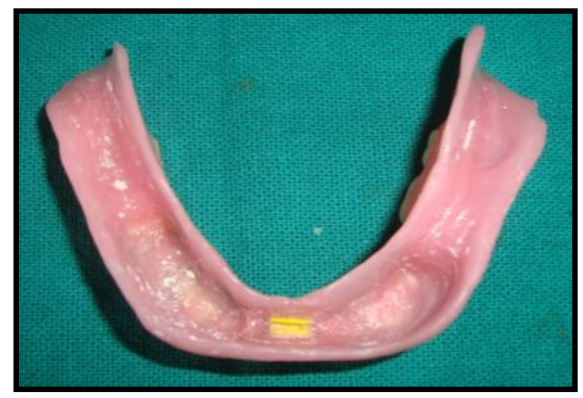

Figure 7. Incorporation of Metal Housing and Hader Clip in the Permanent Denture 